\title{
PHAEOCHROMOCYTOMA: STRATEGY TO MEET THE CHALLENGE
}

\section{Soumitra Mukherjee ${ }^{1}$, Ruchi Gupta ${ }^{2}$, Tirtharatan Ghosh ${ }^{3}$, Utpal Dutta ${ }^{4}$, Sarbari Swaika ${ }^{5}$}

\section{HOW TO CITE THIS ARTICLE:}

Soumitra Mukherjee, Ruchi Gupta, Tirtharatan Ghosh, Utpal Dutta, Sarbari Swaika. "Phaeochromocytoma: Strategy to Meet the Challenge". Journal of Evolution of Medical and Dental Sciences 2015; Vol. 4, Issue 69, August 27; Page: 12087-12091, DOI: $10.14260 /$ jemds/2015/1742

INTRODUCTION: The word phaeochromocytoma is derived from the Greek words phaios, for dusky and chroma, for color. In 1912, Pick ${ }^{1}$ noted that these tumors stained a deep rust color when treated with chromium salts. WHO clarified the nomenclature in 2004 and described phaeochromocytoma as an intra-adrenal paraganglioma. ${ }^{2}$ Although most commonly originates from adrenal medulla; organ of Zuckerkendl, right atrium, spleen, broad ligament of uterus are some of the extra adrenal sites. Less than $0.1 \%$ of all cases of hypertension in adults is caused by phaeochromocytoma. $3,4,5$ Catecholamines or their metabolites secreted from the tumor mass are responsible for the typical presentations of phaeochromocytoma i.e. paroxysmal hypertension, palpitations, headache and sweating. Catecholamine secretion in phaeochromocytoma is not regulated in the same manner as in healthy adrenal tissue. Most phaeochromocytomas secrete norepinephrine predominantly, whereas secretions from normal adrenal medulla are composed of $85 \%$ epinephrine. Approximately 10\% of phaeochromocytomas are malignant. Direct invasion of surrounding tissue or the presence of metastases determine malignancy. ${ }^{6}$

Before resection of tumor, preoperative optimization of the patient is mandatory. Still after adequate optimization, intraoperative haemodynamic instability can occur. So maintaining haemodynamics during perioperative period is a real challenge for the anaesthesiologist. Understanding of exact pathophysiology and availability of effective drugs as well as improved monitoring during intraoperative and postoperative period have reduced the chances of mortality. In this case report, we have described the anaesthetic management of a case of phaeochromocytoma associated with diabetes mellitus that underwent right adrenalectomy with successful results.

CASE REPORT: A 60 years old lady, weighing 58kgs was admitted with complaints of pain in abdomen, facial puffiness and bilateral pedal oedema. Patient was a known hypertensive and was on tab. amlodipine and tab. atenolol $(5 / 25)$ for last 8 to 9 years. She had occasional episodes of palpitations, headache and sweating and provisionally diagnosed her to be a case of phaeochromocytoma. On preoperative evaluation, patient had pallor, oedema, with blood pressure 180/100mmHg, pulse 82/min. Airway assessment showed Mallampati Grade II with adequate mouth opening and restricted neck movement. Systemic examination did not reveal any significant abnormality. Laboratory investigations revealed hemoglobin 9gm/dl, hematocrit 33\%, fasting blood sugar $245 \mathrm{mg} / \mathrm{dl}$, urinary epinephrine $161.60 \mathrm{mcg} /$ day, urinary nor-epinephrine $644.80 \mathrm{mcg} /$ day, urinary metanephrine $>2000 \mathrm{mcg} /$ day, urinary dopamine $276.80 \mathrm{mcg} /$ day. Serum electrolytes, cortisol, thyroid profile, renal function tests remained within normal limits. Electrocardiography revealed anterior wall ischemia in the form of T wave inversion in V2- V6 leads. 2D Echocardiography showed early concentric LVH with good systolic function. Ultrasonography of whole abdomen suggested a heterogeneous solid, cystic mass in the upper part of right adrenal gland measuring 3.3 $\mathrm{cm}$ in diameter. CECT of whole abdomen suggested rounded, hyperdense, soft tissue density SOL in 
right adrenal region measuring $4.2 \mathrm{~cm} \times 3.3 \mathrm{~cm}$. Diagnosis of right adrenal phaeochromocytoma associated with diabetes mellitus was confirmed.

Patient was put on anti-hypertensive agents, insulin and other supportive drugs. Proper hydration was maintained. Blood pressure was controlled by tab. prazosin $1 \mathrm{mg}$ OD to start with and incremented up to $2.5 \mathrm{mg}$ OD, along with tab. amlodipine $5 \mathrm{mg}$ OD and tab. metoprolol 50mg OD. Dose of Insulin was regulated till target blood sugar level was achieved. The patient was then posted for open right adrenalectomy.

Morning dose of oral antihypertensives were given and patient was shifted to operation theatre. Multichannel monitors were attached and urinary catheterization was done. Intravenous cannulations for drug delivery, radial artery cannulation for invasive BP monitoring and right internal jugular vein cannulation for CVP monitoring were done after application of local anaesthetic. Insulin infusion was started and dose regulated according to the sliding scale. 5\% dextrose with half normal saline along with $\mathrm{KCl}$ was started. An epidural catheter was introduced between $\mathrm{T}_{10-11}$ interspace for maintaining perioperative analgesia. Baseline BP, pulse and CVP were 148/84mm Hg, 84/min and $6 \mathrm{~cm}$ of $\mathrm{H}_{2} \mathrm{O}$ respectively. The following drugs were readily available to use in case of emergency - sodium nitroprusside (SNP), nitroglycerin, noradrenaline and adrenaline in form of infusions. Also level 1 pressure pump was standby in case of rapid volume replacement or blood transfusion. SNP infusion pump was attached to one of the peripheral i.v. lines ready to be used when needed.

After preoxygenation, induction of anesthesia was done with i.v. lidocaine $100 \mathrm{mg}$, fentanyl $125 \mathrm{mcg}$, propofol $120 \mathrm{mg}$ and tracheal intubation facilitated by i.v. rocuronium $40 \mathrm{mg}$. Bupivacaine was injected through epidural catheter. Anaesthesia was maintained with $02, \mathrm{~N}_{2} \mathrm{O}$, sevoflurane and rocuronium. Blood sugar was monitored every half an hour and insulin infusion adjusted accordingly. Patient was put on VCV mode.

During the intraoperative period, BP shot up to $225 / 120 \mathrm{~mm} \mathrm{Hg}$ with a heart rate of $130 / \mathrm{min}$ during tumor handling which was managed with sodium nitroprusside infusion. After adrenal vein ligation precipitous hypotension occurred with blood pressure of 86/56mm Hg which was managed with bolus of intravenous fluid and noradrenaline infusion. Inj. Hydrocortisone 200mg was administered after removal of the tumor. Reversal followed by extubation was uneventful. After completion of surgery the patient was shifted to ICU. Haemodynamic support was maintained for next 6 hours in postoperative period. Histopathological examination of the tumor revealed it to be pheochromocytoma.

DISCUSSION: Pheochromocytomas are rare catecholamine secreting tumors that arise from chromaffin tissue of the adrenal medulla and some extra-adrenal sites. Successful surgery for excision of pheochromocytoma was first performed by Roux (1926) and Mayo (1927).7

Preoperative diagnosis is usually made by the clinical features and determination of catecholamines and their metabolites in blood and urine. Recent studies show a higher sensitivity for the determination of urinary normetanephrine and platelet norepinephrine. ${ }^{8} \mathrm{CT}$ scan and MRI are the imaging techniques with sensitivity between $75 \%$ and $100 \%$, but carry a low specificity. In extraadrenal, metastatic and recurrent pheochromocytomas MRI has higher sensitivity than CT scan. The 131I metaiodonebenzylguanide gammagraphy (131-MIBG), despite its low image quality and definition, has $83.5 \%$ sensitivity and, in combination with platelet normetanephrine, it reaches $100 \%$ 
sensitivity. ${ }^{8}$ A PET scan has a better image resolution and, depending on the tracer (18-fluoro dihydroxyphenylalanine), its sensitivity could reach $100 \% .^{9}$

Unfortunately, no reliable clinical, biochemical or histological features distinguish malignant from a benign phaeochromocytoma. ${ }^{6}$ Preoperative evaluation and preparation of the patient, intraoperative management and the postoperative care remain an uphill task for the anaesthesiologist. $25-50 \%$ of hospital deaths in phaeochromocytoma occur during induction of anaesthesia or during operative procedures for other cause. ${ }^{4,10}$ The aims of our preoperative preparation were medical control of BP, correction of intravascular volume, assessment of severity of end-organ damage, normalization of electrolytes and blood glucose and hormonal evaluation of the patient. $3,4,5,11,12,13$

Phenoxybenzamine is widely used since early 1950s as the mainstay of pre and perioperative control of BP but due to chronotropic and inotropic side effects along with persistent central $\alpha_{2}$ adrenoreceptor blockade, it leads to somnolence, headache, stuffy nose and marked refractory postural hypotension. ${ }^{14,15,16} \mathrm{We}$ administered prazosin, a selective $\alpha_{1}$ blocker, preoperatively because of advantages it has over phenoxybenzamine. It does not produce reflex tachycardia, so haemodynamics is better maintained. Its shorter half-life gives liberty of rapid dose adjustment. ${ }^{14}$ Adequacy of dose of prazosin is evaluated by development of postural hypotension and in we achieved this at a dose of $2.5 \mathrm{mg}$ OD.

To limit excessive tachycardia with or without arrhythmias due to increased circulatory epinephrine, selective $\beta_{1}$ adrenoreceptor blocker such as atenolol or bisoprolol is indicated.17,18,19 Second indication of $\beta$ blocker is to attenuate excessive cardiac sympathetic drive secondary to suppression of presynaptic $\alpha_{2}$ receptors. ${ }^{3}$ We used atenolol 50mg OD for this purpose.

In our case amlodipine was given in a dose of $10 \mathrm{mg}$ OD to get the benefit of inhibition of norepinephrine mediated transmembrane $\mathrm{Ca}^{2+}$ influx in vascular smooth muscle.18,19,20,21 Dihydropyridine CCBs do not induce tachycardia and may also reduce catecholamine associated coronary artery spasm, therefore are particularly useful in patients of phaeochromocytoma with coronary artery vasospasm or myocarditis. ${ }^{20,21}$

Labetalol and carvedilol, combined $\alpha$ and $\beta$ blocker, are not commonly used because they have $\alpha: \beta(1: 7)$ activity which is not appropriate as monotherapy preparation.

General anaesthesia is preferred choice in all the cases. The impact of outcome depends on adequate preoperative blockade, recognition of preoperative intravascular volume depletion and heightened vigilance coupled with precise and prompts care of hemodynamic instability. Laparoscopic approach is well tolerated but laparoscopic insufflation has been associated with hypertensive spikes. ${ }^{22}$ Propofol, thiopentone $\mathrm{Na}$, etomidate are all useful intravenous induction agent but ketamine should be avoided. Regarding maintenance $\mathrm{N}_{2} \mathrm{O}$, sevoflurane and isoflurane can be used but desflurane should be avoided. Short acting opioid like fentanyl or remifentanil and intermediate acting muscle relaxant like vecuronium, cis-atracurium, rocuronium lead to prevention of hemodynamic instability by maintaining deep plane of anaesthesia.

Dexmedetomidine, centrally acting $\alpha_{2}$ agonist, may be beneficial as it maintains hemodynamic stability by reducing release of norepinephrine.23,24

A low thoracic epidural blocks sensory and sympathetic discharge in the area of surgical field but it cannot prevent the effects of catecholamine released during surgical manipulation of the tumor. 
CONCLUSION: Phaeochromocytoma is one of the few causes of hypertension that can be treated surgically. Both preoperative optimization and perioperative maintenance of haemodynamics are real challenges from the anaesthesiologist point of view.

Despite certain advances we have in our hand, it is difficult to establish a specific anaesthetic protocol for phaeochromocytoma. The future waits for improvements in management of this disease with further understanding of molecular mechanisms. Until then, a balanced anaesthesia provided by an attentive and experienced anaesthesiologist in an adequately optimized patient is certainly more important than which drug or drug combination is selected.

\section{REFERENCES:}

1. Pick L. Das Ganglioma embryonale sympathicum (Sympathoma embryonale), eine typische bosartige Geschwultsform des sympathischen Nervensystems. Berl kiln Wochenschr 1912; 49: 16-22. (Also Verh Berl Med Ges 1912; 13: 522-557).

2. DeLellis RA LR, Heitz PU, Eng C (Eds). Pathology and Genetics of Tumors of Endocrine Organs. In: World Health Organization of Classification of Tumors. Lyon, France: IARC press; 2004.

3. Prys-Roberts C. Phaeochromocytoma--recent progress in its management. Br J Anaesth. 2000; 85(1):44-57.

4. Pauker SG, Kopelman RI. Interpreting hoofbeats: can Bayes help clear the haze? N Engl J Med. 1992; 327(14):1009-1013.

5. Lenders JW, Eisenhofer G, Mannelli M, Pacak K. Phaeochromocytoma. Lancet. 2005; 366(9486):665-675.

6. Saffar $\mathrm{H}$ etal. Expression of Galectin-3, nm-23, and Cyclooxygenase-2 Could Potentially Discriminate Between Benign and Malignant Pheochromocytoma. American Journal of Clinical Pathology. 2011; 135: 454-460.

7. Welbourn RB. Early surgical history of phaeochromocytoma. Br J Surg 1987; 74: 594-600.

8. Guller U, Turek J, Eubanks S, Delong ER, Oertli D, Feldman JM. Detecting pheochromocytoma: defining the most sensitive test. Ann Surg. 2006 Jan; 243(1):102-107.

9. Ilias I, Yu J, carrasquillo JA et al superiority of 6-[18F] - fluorodopamine positron emission tomography versus [131I] metaiodobenzylguanidine scintigraphy in the localization of metastatic phaeochromocytoma. J Clin Endocrinol Metab 2003; 88: 4083-4087.

10. Sutton MG, Sheps SG, Lie JT. Prevalence of clinically unsuspected pheochromocytoma. Review of a 50-year autopsy series. Mayo Clin Proc. 1981; 56(6):354-360.

11. Peterfreund R, Lee S. Endocrine surgery and intraoperative management of endocrine conditions. In Longnecker Anesthesiology Mc Graw-Hill 2008, 1433-1436.

12. Scherpereel, P. Critical Care Focus Volume 4: Endocrine disturbance. European Journal of Anaesthesiology 2001, 18: 417.

13. Roizen M, Fleisher L. Anesthesia and implication of concurrent disease. In Miller Anesthesia 8th Ed. Churchill-Livinstone 2015: 1170-1171.

14. Hull CJ. Phaeochromocytoma: diagnosis, pre-operative preparation and anaesthetic management. Br J Anaesth 1986; 58: 1453-1468.

15. Iseri LT, Henderson HW, Derr JW. Use of adrenolytic drug, regitine, in phaeochromocytoma. Am Heart J 198; 42:129-136.

16. Khairi MRA, Dexter RN, Burzynski NJ, Johnston CC. Mucosal neuroma, phaeochromocytoma, Medullary carcinoma thyroid: multiple endocrine neoplasia type 3. Medicine 1675; 54: 89-112. 


\section{CASE REPORT}

17. Kinney MA, Narr BJ, Warner MA. Perioperative management of phaeochromocytoma. J Cardiothorac Vasc Anesth 2002; 16: 359-369.

18. Mannelli M. management and treatment of phaeochromocytomas and paragangliomas. Ann $\mathrm{N} \mathrm{Y}$ Acad Sci 2006; 1073: 405-416.

19. Pacak K. Preoperative management of the phaeochromocytoma patient. J Clin Endocrinol Metab 2007; 92: 4069-4079.

20. Bravo EL. Phaeochromocytoma. Curr Ther Endocrinol Metab 1997; 6: 195-197.

21. Lehmann HU, Hochrein H, Witt E et al. Hemodynamic effects of calcium antagonists. Review. Hypertension 1983; 5: 1166-1173.

22. Tauzin Fin P, sesay M, Gosse P, Ballanger P. Effects of perioperative alpha-1 block on hemodynamic control during laparoscopic surgery for phaeochromocytoma. Br J Anaesth. 2004; 92(4):512-517.

23. Schumann R, Hudcova J. Dexmedetomidine infusion during surgery with a patient of phaeochromocytoma. Acta Anaesthesiologica Scandinavica 2010; 54(3):393-394.

24. Wong AYC, Cheung CW. Dexmedetomidine for resection of a large phaeochromocytoma with invasion into the inferior vena cava. Br J Anaesth 2004; 93(6): 873.

AUTHORS:

1. Soumitra Mukherjee

2. Ruchi Gupta

3. Tirtharatan Ghosh

4. Utpal Dutta

5. Sarbari Swaika

\section{PARTICULARS OF CONTRIBUTORS:}

1. Post Graduate Trainee, Department of Anaesthesiology, Bankura Sammilani Medical College and Hospital.

2. Post Graduate Trainee, Department of Anaesthesiology, Bankura Sammilani Medical College and Hospital.

3. Assistant Professor, Department of Anaesthesiology, Bankura Sammilani Medical College and Hospital.

FINANCIAL OR OTHER COMPETING INTERESTS: None
4. Post Graduate Trainee, Department of Anaesthesiology, Bankura Sammilani Medical College and Hospital.

5. Associate Professor, Department of Anaesthesiology, IPGMER.

\section{NAME ADDRESS EMAIL ID OF THE CORRESPONDING AUTHOR:}

Dr. Soumitra Mukherjee, Sarkarpara, Banstala, Rajpur, Kol-149, West Bengal.

E-mail: soumitramukherjee161@yahoo.com

Date of Submission: 28/07/2015.

Date of Peer Review: 29/07/2015.

Date of Acceptance: 21/08/2015.

Date of Publishing: 27/08/2015. 